ISSN 2077-1827. Гуманізація навчально-виховного процесу. 2019, №. 6 (98)

РОЗДІЛ. ВИЩА ШКОЛА

УДК 004:37:001

\title{
ТОПОЛЬНИК Яна
}

доктор педагогічних наук, доцент, професор кафедри педагогіки вищої школи, Державний вищий навчальний заклад «Донбаський державний педагогічний університет»,

вул. генерала Батюка, 19, м. Слов’янськ, 84116, Україна

E-mail: yannetkatop@gmail.com

КАРЕЛІН Михайло

кандидат педагогічних наук, доцент, доцент кафедри педагогіки вищої школи, Державний вищий навчальний заклад «Донбаський державний педагогічний університет»,

вул. генерала Батюка, 19, м. Слов’янськ, 84116, Україна

E-mail: m karelin@ukr.net

\section{ХМАРНІ ТЕХНОЛОГІЇ ІНФОРМАЦІЙНО-КОМУНІКАЦІЙНОЇ ПІДТРИМКИ НАУКОВИХ ДОСЛІДЖЕНЬ МАЙБУТНІХ МАГІСТРІВ ТА ДОКТОРІВ ФІЛОСОФІЇ В ГАЛУЗІ ОСВІТИ}

Анотація. У статті розглянуті аспекти проблеми інформатизації освіти. Звертається увага на те, що на сьогодні науково-дослідницьку діяльність майбутніх науковців неможливо уявити поза розвитком хмарних технологій. Охарактеризовано поняття „комунальні обчислення”, „хмарні обчислення”, „хмара”. Наведено міжнародні документи у галузі хмарних обчислень. Виокремлено базові характеристики хмарних обчислень (самообслуговування за потребою; вільний мережний доступ; об'єднання ресурсів у пул; швидка еластичність; вимірюваність сервісу) та хмарної моделі (масовість застосування; гомогенність інфраструктури; віртуалізація додатків; стійкість виконання обчислень; дешеве програмне забезпечення; географічно розподілене використання; сервісна орієнтованість; передові технології безпеки). Наведено основні компоненти системи хмаро зорієнтованих засобів навчання в освітньому середовищі закладу вищої освіти (система управління навчанням, соціальні мережі, wiki-система, інтегроване хмарне середовище). Охарактеризовано програмні продукти у якості хмаро зорієнтованих засобів навчання (соціальні мережі, Google Docs, Google Apps for Education, програми ведення блогів, програми для проведення вебінарів). Виокремлено електронні ресурси навчального призначення та їх навчальні цілі (підготовка демонстраційних та друкованих матеріалів; опрацювання текстів; демонстрація мультимедіа; розв'язання задач; здійснення практичних, лабораторних робіт; математичні перетворення; моніторинг навчальної діяльності). Наведено напрями застосування хмарних технологій під час інформаційно-комунікаційної підтримки наукових досліджень майбутніх магістрів і докторів філософії в галузі освіти (використання наукометричних баз даних; перевірка наукових робіт на плагіат; використання електронних (C) Топольник Я., Карелін М., 2019 
ISSN 2077-1827. Гуманізація навчально-виховного процесу. 2019, №. 6 (98)

РОЗДІЛ. ВИЩА ШКОЛА

журнальних систем відкритого доступу; проведення моніторингових наукових досліджень; використання наукових соціальних мереж).

Ключові слова: інформатизація освіти, інформаційно-комунікаційна підтримка, комунальні обчислення, хмарні обчислення, хмара, хмаро зорієнтовані засоби навчання, програмний продукт.

Постановка проблеми у загальному вигляді та іï зв'язок 3 важливим науковими чи практичними завданнями. Науководослідницьку діяльність на сьогодні неможливо уявити поза розвитком хмарних технологій (Cloud Technology), які вимагають підключення до Інтернету й передбачають віддалену обробку та зберігання даних, надають доступ до комп'ютерних ресурсів сервера i використання програмного

забезпечення як онлайн-сервісу. Завдяки хмарним технологіям стало можливим виникнення хмаро зорієнтованого навчального середовища (ХОНС) закладу освіти.

Аналіз останніх досліджень і публікацій, в яких започатковано розв'язання даної проблеми i на які спирасться автор, виділення невирішених раніше частин загальної проблеми, котрим присвячується означена стаття. Хмаро зорієнтоване навчальне середовище навчальних закладів різного рівня, його проектування, структурування, можливості використання в навчанні та науково-дослідницькій діяльності широко вивчаються в сучасній науці, зокрема про це йдеться в наукових працях В. Бикова, В. Кухаренка, С. Литвинової, А. Манако, О. Маркової, Л. Панченко, М. Попель, М. Рассовицької, А. Стрюка, С. Семерікова, O. Спіріна, М. Шишкіної, Л. Вагуеро (L. Vaquero), П. Мелла (P. Mell), інших вітчизняних та зарубіжних науковців.

Як зазначають С. Семеріков, О. Маркова, А. Стрюк та ін. [1; 2], теоретичною основою хмарних технологій $\epsilon$ концепція „комунальних обчислень" (Utility Computing), сутність якої у 1961 р. Дж. Маккарті (J. McCarthy, 1927-2011) виклав у доповіді, присвяченій сторіччю Массачусетського технологічного інституту, розглянувши комп'ютерні ресурси (обчислювальні, зберігальні та інші) як вимірювані і гнучко дозовані послуги на зразок тих, що надають оператори зв'язку. Тож історія хмарних технологій бере початок від середини ХХ століття.

Здійснений аналіз праць науковців засвідчив, що в педагогічній науці накопичено певний досвід дослідження проблем становлення інформаційного суспільства, інформатизації освіти, який потребує узагальнення.

Формулювання цілей статті (постановка завдання). Метою статті $\epsilon$ 3'ясування й узагальнення сутності та особливостей використання хмарних технологій ІК-підтримки наукових досліджень майбутніх магістрів та докторів філософії в галузі освіти.

Виклад основного матеріалу дослідження 3 повним обгрунтуванням отриманих наукових результатів. Концепція „комунальних обчислень” еволюціонувала, іiі технологічна реалізація вимагала знаходження балансу між традиційною термінальною (клієнт-серверною) ідеологію і суто 
ISSN 2077-1827. Гуманізація навчально-виховного процесу. 2019, №. 6 (98)

РОЗДІЛ. ВИЩА ШКОЛА

розподіленими системами 3 автобалансуванням потужності, доки не 3'явилися центри опрацювання даних (ЦОД) у їх сучасному вигляді. Запропонована у 1961 р. концепція Дж. Маккарті, була опублікована у 1999 р. Саме відтоді з'явилася сфера комп'ютерних послуг спільного використання, які тепер прийнято називати „хмарними” (Cloud Computing).

За визначенням Національного інституту стандартів США (NIST), під хмарними обчисленнями розуміють модель зручного мережного доступу до загального фонду обчислювальних ресурсів (наприклад, мереж, серверів, файлів даних, програмного забезпечення та послуг), які можуть бути швидко надані при умові мінімальних управлінських зусиль та взаємодії 3 постачальником [3]. У документах NIST було запропоновано п’ять суттєвих (базових) характеристик хмарних обчислень, завдяки яким можна відрізнити ці системи від інших різновидів ІКТ:

- самообслуговування за потребою;

- вільний (повсюдний) мережний доступ;

- об'єднання ресурсів у пул (незалежність від місцезнаходження pecypcy);

- швидка еластичність (надання і вивільнення ресурсу в потрібній кількості і у будь-який час);

- $\quad$ вимірюваність сервісу (оплата по факту надання).

Також було визначено загальні характерні властивості хмарної моделі використання сервісів:

- $\quad$ масовість (великі масштаби) застосування;

- гомогенність (однорідність) інфраструктури;

- віртуалізація додатків (організація доступу до програмного забезпечення) як технологія використання та постачання програмного забезпечення (програмних рішень) без встановлення його на персональному комп'ютері користувача;

- стійкість (надійність) виконання обчислень;

- дешеве програмне забезпечення;

- географічно розподілене використання;

- сервісна орієнтованість;

- передові технології безпеки [3].

Отже, хмарні обчислення стали основою хмарних технологій.

Проблеми проектування сервісів і технологій хмарних обчислень для використання у навчальному процесі закладів освіти належать до першочергових у сфері інформатизації. Про це свідчить ряд урядових ініціатив та прийняття міжнародних документів, започаткування масштабних освітніх проектів у США, Мексиці, Японії, країнах Свросоюзу, Росії, Японії, численних конференцій та наукових видань 3 даної тематики.

Серед міжнародних документів у галузі хмарних обчислень, виданих в останні роки:

- Свропейський цифровий порядок денний (A Digital Agenda for Europe, 2010 p.) [4]; 
ISSN 2077-1827. Гуманізація навчально-виховного процесу. 2019, №. 6 (98)

РОЗДІЛ. ВИЩА ШКОЛА

- Федеральна урядова ініціатива хмарних обчислень у США (Federal Cloud Computing Strategy, 2011 р.), за якою сфера хмарних технологій визнається пріоритетним напрямом технологічного розвитку країни. Згідно даного документу здійснюється ряд заходів, спрямованих на якнайширше сприяння впровадженню хмарних технологій у діяльність підприємств i організацій приватного та державного сектору [5];

- Стратегія хмарних обчислень у Європі (Unleashing the Potential of Cloud Computing in Europe), 2012 p. [6];

- Рекомендації Національного інституту стандартів США (The NIST Definition of Cloud Computing, 2012 р.); визначено стратегічні ініціативи щодо пріоритетних вимог у сфері хмарних технологій, серед яких: технічна переносимість (portability), сумісність (interoperability), надійність (reliability), придатність для підтримування, налагоджування (maintainability), вимоги безпеки (security requirements) [3].

Відзначимо, що поняття „хмари” увійшло до наукового обігу в 2000-х роках, зокрема в Україні, як вказують Ю. Носенко, М. Попель, М. Шишкіна, його починають вживати с 2008 року, але під хмарою в той час розуміли безкоштовні хостинги поштових служб для студентів та викладачів. Усі інші інструменти, які наразі пропонують для використання в хмарі, були відсутні через недостатність інформації та брак навичок використання [7].

Зарубіжні науковці (Л. Вакуеро (L. Vaquero) та ін.), аналізуючи наявні потрактування поняття „хмара” в контексті IKT, дійшли висновку, що в загальному значені „хмара” - це великий масив легкодоступних віртуальних ресурсів (апаратних, програмних платформ та послуг). Ці ресурси можуть динамічно змінюватись, щоб пристосуватися до змін навантаження (масштабування), що зумовлює оптимальне їх використання [8].

Хмарне освітньо-наукове середовище, яке виникає завдяки функціонуванню й системному використанню хмаро зорієнтованих засобів навчання, наразі характеризує інформаційний простір практично кожного закладу вищої освіти.

На думку А. Стрюка до основних компонентів системи хмаро зорієнтованих засобів навчання в освітньому середовищі закладу вищої освіти (на прикладі кафедри моделювання та програмного забезпечення ДВНЗ „Криворізький національний університет”) належать:

- система управління навчанням, що реалізована на базі відкритої платформи MOODLE;

- соціальні мережі, серед яких за результатами опитування серед студентів усе більшої популярності набувають Facebook-подібні мережі;

- $\quad$ wiki-система, реалізована на базі відкритої платформи MediaWiki;

- інтегроване хмарне середовище на базі відкритої системи OwnCloud [2].

Особливу ефективність, на думку науковців (А. Стрюк, М. Рассовицька [2]), має побудова корпоративної кафедральної хмари 3 метою спрощення доступу викладачів до кафедральних документів; забезпечення спільної 
роботи над методичними посібниками, підручниками тощо; організації спільної роботи студентів з курсового і дипломного проектування, виконання спільних проектів, передбачених різними дисциплінами. Для програмного забезпечення приватної кафедральної хмари А. Стрюк та М. Рассовицька рекомендують платформу OwnCloud, яка має такі технічні переваги:

- простота розгортання й адміністрування;

- помірні системні вимоги;

- відкритий код;

- підтримка спільнотою розробників [2].

В. Кухаренко та ін., аналізуючи можливості використання хмарних технологій у реалізації змішаного навчання [9], акцентують увагу на виконанні програм, розташованих на зовнішніх серверах (програмне забезпечення як послуга чи SAAS), що наразі стає популярним у навчальній практиці. На думку вчених, у такому підході: програмне забезпечення відстежується й контролюється; управління версіями програмного забезпечення спрощено; небезпеки розповсюдження вірусів зводяться до мінімуму; вихідні дані й отримані файли можна зберігати, управляти централізовано на серверах брандмауерів; можна працювати на простих конфігураціях комп'ютерів [9, с. 53].

Науковцями виокремлено низку програмних продуктів, які найчастіше використовуються в освітньому процесі у якості хмаро зорієнтованих засобів навчання:

1. Соціальні мережі, зокрема, Twitter (засновано 2006 р.), який дозволяє розміщувати оголошення, надавати посилання, проводити опитування, читати повідомлення видатних діячів науки, політики та ін. В освітньому процесі Twitter корисний для отримання даних, думок студентів; надання інформації, створення проблем і питань для обговорення, супроводу інформації авторитетного викладача або вченого та аналізу його діяльності.

2. Google Docs - розроблений Google безкоштовний мережевий офісний пакет, що включає текстовий, табличний редактор i службу для створення презентацій. Це веб-орієнтована програма, що працює в рамках веб-браузера без установлення на комп'ютер користувача. Документи i таблиці, що створюються користувачем, зберігаються на сервері Google, або можуть бути збережені у файл. Це одна 3 ключових переваг програми, оскільки доступ до введених даних може здійснюватися 3 будь-якого комп’ютера, під’єднаного до Інтернету. Доступ до особистих документів захищений паролем.

3. Google Apps for Education - це набір хмарних сервісів, які надаються компанією Google безкоштовно для освітніх установ. Завдяки використанню сервісів Google Apps для навчальних закладів є можливість створити сучасні умови для співпраці співробітників, студентів та викладачів: один акаунт (з доменного імені nubip.edu.ua) гарантує доступ до колекції сервісів (можна розширювати й поповнювати); авторизований доступ учасників до хмарного середовища навчального закладу; конфіденційність, безпека, відсутність сторонньої реклами; можливість організації всіх видів 
ISSN 2077-1827. Гуманізація навчально-виховного процесу. 2019, №. 6 (98)

РОЗДІЛ. ВИЩА ШКОЛА

освітньої діяльності; освітній контент зберігається і структурується в одному місці; можливість інтеграції стороннього П3; аналітика за напрямами діяльності університету.

4. Програми ведення блогів для обговорення, обміну інформацією та спілкування; ведення блогу викладачем доцільно для оприлюднення аналізу публікацій, поглядів на певні проблеми, роздумів тощо. Інформація блогу публічна, іiі можуть бачити студенти та колеги, вона може перетворюватися в доповіді на конференціях, статті, завдання для учнів, у свою чергу всіх відвідувачів блогу видно.

5. Програми для проведення вебінарів - нового засобу спілкування, групової роботи в Інтернеті з використанням сучасних засобів комунікації відео, флеш і чат. Програмне забезпечення для проведення вебінарів, як правило, дозволяє: демонструвати документи в найбільш поширених форматах; передавати голос і відео зображення ведучого й кількох учасників; спілкуватися в чаті; демонструвати відеоролики; малювати графічні об'єкти й набирати текст на білій дошці; здійснювати перехоплення екрану комп'ютера; розміщувати файли для обміну; проводити опитування слухачів.

М. Шишкіна виокремлює такі електронні ресурси навчального призначення (ЕРНП, хмаро зорієнтовані засоби навчального призначення) у складі хмаро зорієнтованого середовища: ресурси е-журнальних систем, ебібліотек, інформаційно пошукових мереж; збірки, колекції, бібліотеки мультимедійних матеріалів; ЕОР довідкові та додаткові; текстові редактори, редактори таблиць, зображень, презентацій; інструментальні засоби для створення ЕОР; електронні підручники, посібники; електронні навчальні курси; програми лінгвістичного аналізу; навчальні експертні системи; етезауруси; електронні задачники; предметні пакети прикладних програм (ППП); пакети прикладних програм моделювання; програми-тренажери, навчальні лабораторні практикуми; діяльнісні середовища; системи етестування; автоматизовані системи оцінювання знань [10].

ЕРНП використовуються, як справедливо вказує М. Шишкіна, 3 різними навчальними цілями:

- для підготовки демонстраційних та друкованих матеріалів, опрацювання навчальної, довідкової літератури;

- для опрацювання текстів, формулювання тверджень, понять, висновків, синтаксичного та семантичного опрацювання текстів;

- демонстрації мультимедіа;

- для розв’язання задач, вправ, відпрацювання навичок;

- $\quad$ здійснення практичних, лабораторних робіт, моделювання, аналізу й опрацювання даних;

- побудови, обчислення, математичних перетворень;

- оцінювання, моніторингу навчальної діяльності [10].

Під час ІК-підтримки наукових досліджень майбутніх магістрів i докторів філософії в галузі освіти хмарні технології застосовуються у наступних напрямах: 
ISSN 2077-1827. Гуманізація навчально-виховного процесу. 2019, №. 6 (98)

РОЗДІЛ. ВИЩА ШКОЛА

- використання наукових соціальних мереж, наукометричних баз даних та систем індексування наукової продукції (Scopus, Web of Science, Google Scholar (Google), Index Copernicus, Бібліометрика української науки);

- перевірка наукових робіт на плагіат (Plagiarism Checker, AntiPlagiarism, Advego Plagiatus, Double Content Finder, PaperRater та ін.);

- використання електронних журнальних систем відкритого доступу як засобу інформаційно-аналітичної підтримки та оприлюднення результатів наукової діяльності (OJS (Open Journal System), Joomla!);

- використання хмарних сервісів для проведення моніторингових наукових досліджень;

- використання наукових соціальних мереж.

Висновки 3 даного дослідження і перспективи подальших розвідок у даному напрямку. Хмарні сервіси й інформаційні ресурси широко використовуються у відкритому науково-освітньому просторі України. Хмарні сервіси визнаються перспективним напрямом розвитку програмного забезпечення і послуг сучасного цифрового світу, зокрема цифрової науки.

3 одного боку, за допомогою хмарного середовища здійснюється ресурсна підтримка інших засобів ІКТ навчання, 3 іншого, хмарне середовище виступає як самостійний засіб навчання, за допомогою якого вирішуються окремі навчальні задачі.

Перспективним вважаємо подальше вивчення основних пріоритетів та особливостей використання хмарних технологій під час підготовки майбутніх науковців у закладах вищої освіти, створення хмарного освітньо-наукового середовища, розвитку цифрової науки.

\section{СПИСОК ВИКОРИСТАНОЇ ЛІТЕРАТУРИ}

1. Маркова О. М., Семеріков С. О., Стрюк А. М. Хмарні технології навчання: витоки. Інформаційні технологї $і$ засоби навчання, 2015. Том 46, № 2. С. $29-44$.

2. Стрюк А., Рассовицька М. Система хмаро орієнтованих засобів навчання як елемент інформаційного освітньо-наукового середовища ВН3. Інформаційні технологї $i$ засоби навчання, 2014. Том 42. № 4. URL : https://journal.iitta.gov.ua/index.php/itlt/article/view/1087

3. Mell P., Grance T. The NIST Definition of Cloud Computing : Recommendation of the National Institute of Standards and Technology. Gaitherburg : National Institute of Standards and Technology, September 2011. (Special Publication 800-415). URL : http://csrc.nist.gov/publications/nistpubs/800-145/SP800-145.pdf

4. A Digital Agenda for Europe / Communication from the Commission to the European Parliament, the Council, the European Economic and Social Committee and the Committee of the Regions. Brussels, 19.5.2010. 245 final.

URL : http://eur-lex.europa.eu/legalcontent/EN/TXT/PDF/?uri=CELEX:52010DC0245R(01)\&from=EN 
ISSN 2077-1827. Гуманізація навчально-виховного процесу. 2019, №. 6 (98)

РОЗДІЛ. ВИЩА ШКОЛА

5. Federal Cloud Computing Strategy. URL : http://www.dhs.gov/sites/default/files/publications/digital-strategy/federalcloud-computing-strategy.pdf

6. Unleashing the Potential of Cloud Computing in Europe. European Commission. Brussels, 27.9.2012COM, 2012. 529 final. URL : http://ec.europa.eu/information society/activities/cloudcomputing/docs/com/ com cloud.pdf

7. Хмарні сервіси і технології у науковій і педагогічній діяльності : Методичні рекомендації / укл. : Ю. Г. Носенко, М.В.Попель, М. П. Шишкіна; за ред. М. П. Шишкіної. К. : ІІТЗН НАПН України, $2016.73 \mathrm{c}$.

8. Vaquero L., Rodero-Merino L., Caceres J. \& Lindner M. A Break in the Clouds: Towards a Cloud Definition. ACM SIGCOMM Computer Communication Review, 2009. Vol. 39. Iss. 1. P. 50 - 55.

9. Кухаренко В. М. Системний підхід до змішаного навчання. Інформаційні технології в освіті, 2015. № 24. С. 53 - 67.

10.Шишкіна М. П., Попель М. В. Хмаро орієнтоване середовище навчального закладу: сучасний стан i перспективи розвитку досліджень. Інформаційні технологї̈ $і$ засоби навчання, 2013. № 5(37). URL : http://journal.iitta.gov.ua/index.php/itlt/article/view/903/676

Стаття надійшла до редакції 20.11.2019.

\section{тОПОЛЬНИк Яна}

доктор педагогических наук, доцент, профессор кафедры педагогики высшей школы, Государственное высшее учебное заведение «Донбасский государственный педагогический университет»,

ул. генерала Батюка, 19, г. Славянск, 84116, Украина

E-mail: yannetkatop@,gmail.com

\section{КАРЕЛИН Михаил}

кандидат педагогических наук, доцент, доцент кафедры педагогики высшей школы, Государственное высшее учебное заведение «Донбасский государственный педагогический университет»,

ул. генерала Батюка, 19, г. Славянск, 84116, Украина

E-mail: m karelin@ukr.net

ОБЛАЧНЫЕ ТЕХНОЛОГИИ ИНФОРМАЦИОННОКОММУНИКАЦИОННОЙ ПОДДЕРЖКИ НАУЧНЫХ ИССЛЕДОВАНИЙ БУДУЩИХ МАГИСТРОВ И ДОКТОРОВ ФИЛОСОФИИ В ОБЛАСТИ ОБРАЗОВАНИЯ

Резюме. В статье рассмотрены аспекты проблемы информатизации образования. Обращается внимание на то, что сегодня научноисследовательскую деятельность будущих ученых невозможно представить вне развития облачных технологий. Охарактеризованы понятия „коммунальные вычисления”, „облачные вычисления”, „облако”. Приведены международные документы в области облачных вычислений. Выделены базовые характеристики облачных вычислений и облачной модели. 
Приведены основные компоненты системы облако ориентированных средств обучения в образовательной среде учреждения высшего образования (система управления обучением, социальные сети, wiki-система, интегрированная облачная среда). Охарактеризованы программные продукты в качестве облако ориентированных средств обучения (социальные сети, Google Docs, Google Apps for Education, программы ведения блогов, программы для проведения вебинаров). Выделены электронные ресурсы учебного назначения и их учебные цели. Приведены направления применения облачных технологий при информационно-коммуникационной поддержке научных исследований будущих магистров и докторов философии в области образования.

Ключевые слова: информатизация образования, информационнокоммуникационная поддержка, коммунальные вычисления, облачные вычисления, облако, облако ориентированные средства обучения, программный продукт.

\section{TOPOLNYK Yana}

Professor of Higher School Pedagogy Department, the Doctor of Pedagogical Sciences, State Higher Educational Establishment "Donbas state pedagogical university",

General Batyuk Str., 19, Slovyansk, 84116, Ukraine

E-mail: yannetkatop@,gmail.com

\section{KARELIN Mykhailo}

Associate professor of Higher School Pedagogy Department, the Candidate of Pedagogical Sciences, State Higher Educational Establishment "Donbas state pedagogical university",

General Batyuk Str., 19, Slovyansk, 84116, Ukraine

E-mail: $\underline{\text { m karelin@ukr.net }}$

CLOUD TECHNOLOGIES FOR INFORMATION AND COMMUNICATION SUPPORT FOR SCIENTIFIC RESEARCH OF FUTURE MASTERS AND DOCTORS OF PHILOSOPHY IN THE FIELD OF EDUCATION

Summary. In the article the aspects of the education informatization problem are considered. Attention is drawn to the fact that, today, the scientific activity of future scientists cannot be imagined beyond the development of cloud technologies. The concepts of ,communal computing”, ,cloud computing”, „cloud” are characterized. The international documents in the field of cloud computing are presented. The basic characteristics of cloud computing and cloud model are identified. The main components of the cloud-oriented learning system in the higher education institution's educational environment (training management system, social networks, wiki system, integrated cloud environment) are presented. Software as cloud-based learning tools (social networks, Google Docs, Google Apps for Education, blogging programs, webinar programs) are characterized. 
Electronic educational resources and their educational purposes are identified. The directions of application of cloud technologies during information and communication support of scientific researches of the future masters and doctors of philosophy in the field of education are presented.

Keywords: education informatization, information and communication support, utility computing, cloud computing, cloud, cloud oriented learning tools, software.

Abstract. Introduction. Today, scientific activity cannot be imagined beyond the development of cloud-based technologies that require internet connection and provide for remote processing and storage of data, access to computering resources of server and the use of software as an online service.

Analysis of publications. Theoretical foundations of the cloud oriented educational environment of different levels educational institutions were investigated by such domestic and foreign scientists as: V. Bykov, V. Kukharenko, S. Litvinova, A. Manako, O. Markova, L. Panchenko, M. Popel, M. Rassovitskaya, A. Stryuk, S. Semerikov, O. Spirin, M. Shishkina, L. Vaquero, P. Mell.

Purpose. Find out and summarize the essence and features of the cloud technologies during information and communication support of scientific researches of the future masters and doctors of philosophy in the field of education.

Results. According to the definition of the National Institute of Standards (NIST), cloud computing is a model of convenient network access to a common pool of computing resources (such as networks, servers, data files, software and services) that can be quickly provided with minimal management effort and interaction with the supplier.

Among the international documents in the field of cloud computing, issued in recent years, are: A Digital Agenda for Europe, 2010 p.; Federal Cloud Computing Strategy, 2011 p., in which the field of cloud technologies is recognized as a priority direction of technological development of the country; Unleashing the Potential of Cloud Computing in Europe, 2012 p.; The NIST Definition of Cloud Computing, $2012 \mathrm{p}$., in which identified strategic initiatives on priority requirements in the cloud technologies field.

Generally speaking, the cloud is a large array of easily accessible virtual resources (hardware, software platforms and services). These resources can be dynamically modified to accommodate changes to load (scaling), which optimize their use.

The main components of the cloud-oriented learning system in the higher education institution's educational environment include: training management system, social networks, wiki system, integrated cloud environment.

Scientists have identified a number of software products that are most commonly used in the educational process as cloud-oriented learning tools: social networks, Google Docs, Google Apps for Education, blogging programs, webinar programs.

Electronic resources for educational purposes within the cloud-oriented environment as follows: resources of e-journal systems, e-libraries, information retrieval networks; collections, libraries of multimedia materials; EER background 
and additional; text editors, editors of tables, images, presentations; tools for creating an EER; electronic textbooks, manuals; electronic training courses; linguistic analysis programs; training expert systems; e-thesauri; electronic tasks; subject software packages (SP); modeling software packages; simulator programs, educational laboratory workshops; activity environments; e-testing systems; automated knowledge assessment systems.

Cloud technologies are used during information and communication support of scientific researches of the future masters and doctors of philosophy in the field of education in the following directions: use of scientific social networks, scientometric databases and indexing systems for scientific products (Scopus, Web of Science, Google Scholar (Google), Index Copernicus, Bibliometrics of Ukrainian Science); check of scientific works to plagiarism (Plagiarism Checker, Anti-Plagiarism, Advego Plagiatus, Double Content Finder, PaperRater etc.); use of open access electronic journal systems as a means of informational-analytical support and publication of the scientific activity results (OJS (Open Journal System), Joomla!); use of cloud services for holding monitor scientific researches; use of scientific social networks.

Conclusion. Cloud services and information resources are widely used in the open scientific and educational space of Ukraine.

We consider it a promising further study of the main priorities and features of use of cloud technologies in the preparation of future scientists in higher education institutions, creation of a cloud educational and scientific environment, development of digital science.

\section{REFERENCES}

1. Markova, O.M., Semerikov, S.O., \& Striuk, A.M. (2015). Khmarni tekhnolohii navchannia: vytoky [Cloud learning technologies: the origins]. Informatsiini tekhnolohii $i$ zasoby navchannia - Information technologies and learning tools, 46, 2, 29-44 [in Ukrainian].

2. Striuk, A., Rassovytska, M. (2014). Systema khmaro oriientovanykh zasobiv navchannia yak element informatsiinoho osvitno-naukovoho seredovyshcha VNZ [The system of cloud-oriented learning tools as an element of the educational and scientific environment of universities]. Informatsiini tekhnolohii $i$ zasoby navchannia - Information technologies and learning tools, $42, \quad 4.4$ Retrieved https://journal.iitta.gov.ua/index.php/itlt/article/view/1087 [in Ukrainian].

3. Mell, P., \& Grance, T. (2011). The NIST Definition of Cloud Computing : Recommendation of the National Institute of Standards and Technology. Gaitherburg : National Institute of Standards and Technology. (Special Publication 800-415). Retrieved from http://csrc.nist.gov/publications/nistpubs/800-145/SP800-145.pdf

4. A Digital Agenda for Europe / Communication from the Commission to the European Parliament, the Council, the European Economic and Social Committee and the Committee of the Regions. Brussels, 19.5.2010. 245 final. 
ISSN 2077-1827. Гуманізація навчально-виховного процесу. 2019, №. 6 (98)

РОЗДІЛ. ВИЩА ШКОЛА

Retrieved from http://eur-lex.europa.eu/legalcontent/EN/TXT/PDF/?uri=CELEX:52010DC0245R(01)\&from=EN

5. Federal Cloud Computing Strategy. Retrieved from http://www.dhs.gov/sites/default/files/publications/digital-strategy/federalcloud-computing-strategy.pdf

6. Unleashing the Potential of Cloud Computing in Europe. European Commission. Brussels, 27.9.2012COM, 2012. 529 final. Retrieved from http://ec.europa.eu/information_society/activities/cloudcomputing/docs/com/ com cloud.pdf

7. Nosenko, Yu.H., Popel, M.V., \& Shyshkina, M.P. (2016). Khmarni servisy $i$ tekhnolohii u naukovii $i$ pedahohichnii diialnosti : Metodychni rekomendatsii [Cloud services and technologies in scientific and pedagogical activity: Guidelines]. M.P. Shyshkina (Ed.). Kyiv : IITZN NAPN Ukrainy [in Ukrainian].

8. Vaquero, L., Rodero-Merino, L., Caceres, J. \& Lindner, M.A (2009). Break in the Clouds: Towards a Cloud Definition. ACM SIGCOMM Computer Communication Review, 39, 1, 50-55.

9. Kukharenko, V.M. (2015). Systemnyi pidkhid do zmishanoho navchannia [A systematic approach to blended learning]. Informatsiini tekhnolohii $v$ osviti - Information technologies in education, 24, 53-67 [in Ukrainian].

10. Shyshkina, M.P., \& Popel, M.V. (2013). Khmaro oriientovane seredovyshche navchalnoho zakladu: suchasnyi stan i perspektyvy rozvytku doslidzhen [Cloud-oriented environment of the educational institution: current state and prospects of research development]. Informatsiini tekhnolohii $i$ zasoby navchannia - Information technologies and learning tools, 5(37). from http://journal.iitta.gov.ua/index.php/itlt/article/view/903/676 [in Ukrainian].

(переклала на англ. мову зроблено Я. Топольник - доктором педагогічних наук, доцент,ом професором кафедри педагогіки вищої школи, Державний вищий навчальний заклад «Донбаський державний педагогічний університет»). 